\title{
IMPELEMENTASI SISTEM PEMANTAUAN OBJEK BERGERAK DENGAN MEMANFAATKAN FREKUENSI RADIO MENGGUNAKAN GPS (GLOBAL POSITIONING SISTEM)
}

\author{
Abdul Jabbar Lubis ${ }^{1}$ \\ E-mail: abduljabbarlbs@yahoo.co.id
}

Diterima : 20 Juli 2010/Disetujui : 23 Agustus 2010

\begin{abstract}
The GPS was developed by the United States Department of Defense as a reliable means for accurate navigation. The system provides highly accurate position and velocity information and precise time on a continuous global basis to an unlimited number of properly equipped users. By using combined GPS receiver and microcontroller together with radio system, we can design a monitoring system for our vehicles and display the result on the computer. This system consists of a master module that transmites and receives signals from computer and two slave modules to collect GPS data from vehicles. The result of experiment shows that this system is able to track the vehicle on digital map with accuracy as high as $95 \%$.
\end{abstract}

Keywords: GPS, Microcontroller, Monitoring, $R F$

Perkembangan teknologi navigasi yang pesat saat ini menghasilkan suatu sistem navigasi yang sangat canggih yang dapat digunakan untuk mengetahui posisi suatu objek di permukaan bumi. Sistem ini dikenal dengan nama $G P S$, secara garis besar GPS dibagi menjadi 3 bagian: (1) space segment, (2) control segment, dan (3) user segment. Space segment merupakan bagian dari GPS yang terdiri dari beberapa satelit yang mengorbit di sekeliling bumi, sedangkan control segment terdiri dari beberapa stasiun yang berada di bumi dan bertugas untuk mengontrol

1. Dosen Jurusan Teknik Informatika, STMIK Raharja

J1. Jend. Sudirman No. 40 Cikokol - Tangerang Telp. 5529692 
dan melakukan koreksi terhadap orbit satelit. Bagian ketiga dari GPS atau yang disebut dengan user segment adalah perangkat GPS receiver yang dijual di pasaran dan berfungsi untuk menerima data dari satelit,menerjemahkannya ke dalam satuan posisi koordinat bumi (Dana, 2007).

Dengan menggunakan GPSyang terintegrasi dengan sistem telekomunikasi, maka suatu objek dapat dipantau keberadaannya secara continue dan datadata posisi objek tersebut dapat disimpan ke dalam suatu memori untuk dipergunakan sebagai referensi (yang pada bahasan selanjut-nya disebut dengan data logging). Selain dapat digunakan sebagai data logging, GPS juga dapat digunakan untuk melakukan pemantauan secara berkala terhadap objek yang bergerak sehingga keberadaan objek tersebut dapat diketahui dengan mudah di mana posisinya saat ini.

Yang menjadi masalah adalah jenis sistem telekomunikasi apa yang akan digunakan untuk proses mo ni toring ma upu $\mathrm{n}$ da ta log ging. P ada al at transportasi seperti mobil dan kereta api GPS diintegrasikan dengan perangkat Global System Mobile Comunication (GSM) yang digunakan sebagai media untuk proses transmisi data antara alat transportasi dengan monitoring center.

Sistem tersebut membutuhkan biaya operasional yang cukup besar, di mana pengguna harus mengeluarkan biaya pulsa setiap melakukan transmisi data. Selain itu, pengguna harus menambahkan peralatan GSM pada kendaraan yang akan dipantau, sedangkan jenis kendaraan yang digunakan sebagai alat transportasi, hampir semuanya memiliki perangkat radio yang digunakan sebagai media komunikasi.Tentu sajahal ini sangat membutuhkan biaya yang tidak sedikit dan kurang efisien dalam penerapannya.

Pada penelitian ini, penulis mencoba untuk membuat monitoring system dan data logging pada mobil dengan memanfaatkan frekuensi radio. Secara garis besar frekuensi radio berada pada range $3 \mathrm{~Hz}$ sampai dengan $300 \mathrm{GHz}$, yang dibagi menjadi beberapa bagian dan fungsi dapat dilihat pada Tabel 1 
Tabel 1 Pembagian Frekuensi dan Fungsinya

\begin{tabular}{|c|c|c|c|c|}
\hline Name & Symbol & Range & Wavelength & Applications \\
\hline $\begin{array}{l}\text { Extremely Low } \\
\text { Frequency }\end{array}$ & ELF & 3 to $30 \mathrm{~Hz}$ & $\begin{array}{l}10.000 \text { to } \\
100.000 \mathrm{~km}\end{array}$ & Communication with submarines \\
\hline $\begin{array}{l}\text { Super Low } \\
\text { Frequency }\end{array}$ & SLF & 30 to $300 \mathrm{~Hz}$ & $\begin{array}{l}1.000 \text { to } \\
10.000 \mathrm{~km}\end{array}$ & AC power grids \\
\hline $\begin{array}{l}\text { Ultra Low } \\
\text { Frequency }\end{array}$ & ULF & $\begin{array}{l}300 \mathrm{~Hz} \text { to } \\
3 \mathrm{kHz}\end{array}$ & $\begin{array}{l}100 \text { to } 1.000 \\
\mathrm{~km}\end{array}$ & Communication with mines \\
\hline $\begin{array}{l}\text { Very Low } \\
\text { Frequency }\end{array}$ & VLF & 3 to $30 \mathrm{kHz}$ & 10 to $100 \mathrm{~km}$ & $\begin{array}{l}\text { Audible range } 20 \mathrm{~Hz} \text { to } 20 \mathrm{kHz} \text { (to be audible, } \\
\text { energy must be simply converted to sound) }\end{array}$ \\
\hline Low Frequency & LF & $\begin{array}{l}30 \text { to } 300 \\
\mathrm{kHz}\end{array}$ & 1 to $10 \mathrm{~km}$ & $\begin{array}{l}\text { Int emational broadcasting, navigational beacons, } \\
\text { lowkER }\end{array}$ \\
\hline $\begin{array}{l}\text { Medium } \\
\text { Frequency }\end{array}$ & MF & $\begin{array}{l}300 \text { to } 3000 \\
\mathrm{kHz}\end{array}$ & $\begin{array}{l}100 \mathrm{~m} \text { to } \\
1 \mathrm{~km}\end{array}$ & $\begin{array}{l}\text { Navigational beacons, AM broadcasting, maritime } \\
\text { and aviation communication }\end{array}$ \\
\hline $\begin{array}{l}\text { High } \\
\text { Frequency }\end{array}$ & $\mathrm{HF}$ & 3 to $30 \mathrm{MHz}$ & 10 to $100 \mathrm{~m}$ & Shortwave, citizens band radio \\
\hline $\begin{array}{l}\text { Very High } \\
\text { Frequency }\end{array}$ & VHF & $\begin{array}{l}30 \text { to } 300 \\
\mathrm{MHz} \\
300 \text { to } 3000\end{array}$ & 1 to $10 \mathrm{~m}$ & FM broadcasting broadcast television, aviation \\
\hline $\begin{array}{l}\text { Frequency } \\
\text { Super High }\end{array}$ & SHF & $\begin{array}{l}\mathrm{MHz} \\
3 \text { to } 30 \mathrm{GHz}\end{array}$ & 1 to $10 \mathrm{~cm}$ & $\begin{array}{l}\text { networking, microwave ovens } \\
\text { Wireless networking, radar, satellite links }\end{array}$ \\
\hline $\begin{array}{l}\text { Frequency } \\
\text { Extremely High } \\
\text { Frequency }\end{array}$ & EHF & $\begin{array}{l}30 \text { to } 300 \\
\mathrm{GHz}\end{array}$ & 1 to $10 \mathrm{~mm}$ & $\begin{array}{l}\text { Microw ave data links, radio astronomy, re mote } \\
\text { sensing, advanced weapons systems, advanced } \\
\text { security scanning }\end{array}$ \\
\hline
\end{tabular}

Frekuensi radio yang digunakan pada penelitian adalah frekuensi Ultra High Frequency $(U H F)$ dan perangkat radio yang digunakan adalah Handy Talky $(H T)$.

\section{METODE}

Keseluruhan sistem yang dibuat pada penelitian ini sesuai dengan blok diagram pada Gambar 1

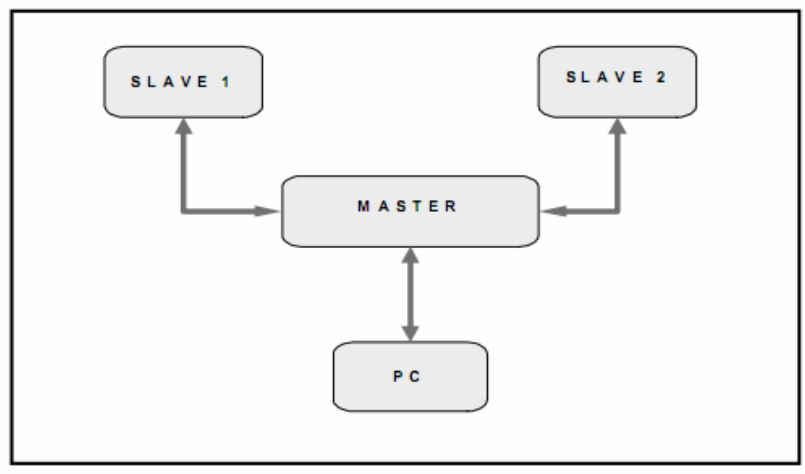

Gambar 1 Blok Diagram Umum

Dari blok diagram pada Gambar 1, dapat diuraikan lagi menjadi beberapa diagram yang lebih spesifik, seperti terlihat pada Gambar 2 dan Gambar 3. 


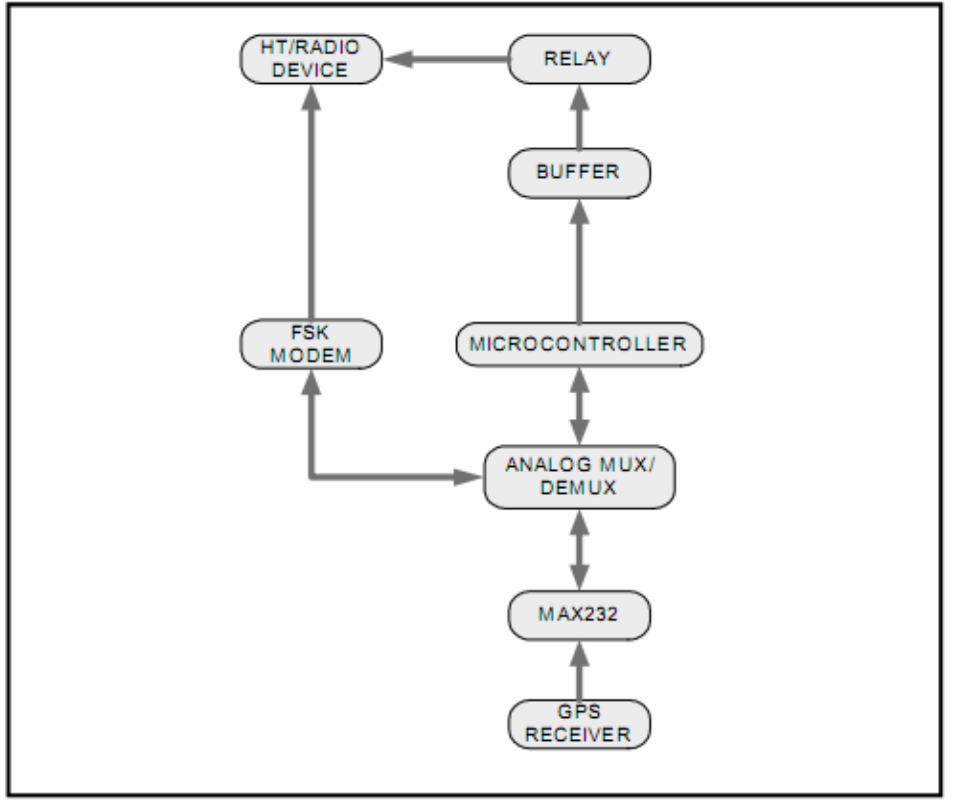

Gambar 2 Blok Diagram Slave

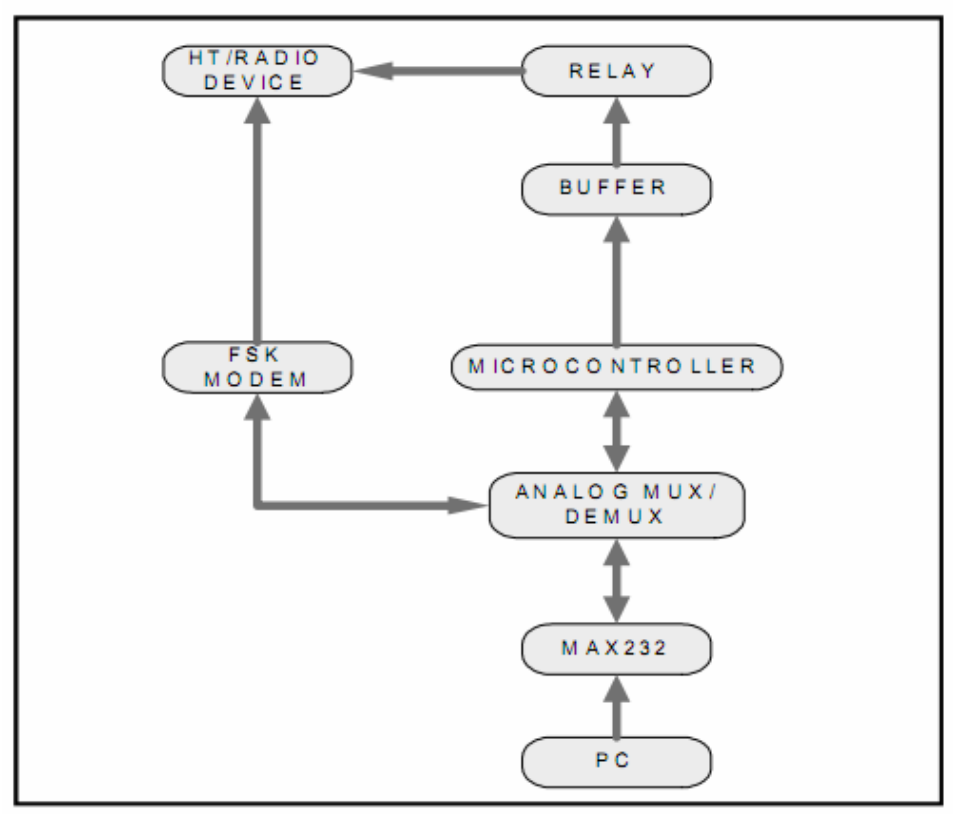

Gambar 3 Blok Diagram Master 


\section{Perancangan Perangkat Keras}

Berdasarkan fungsinya perangkat keras dikelompokkan menjadi beberapa bagian, yaitu Microcontroller AT89S52, GPS receiver, rangkaian relay, modem Frequency Shift Keying (FSK) Microcontroller AT89S52 (Brey, 2002) berfungsi sebagai pusat pengendali yang mengaturkinerja dari masing-masing hardware yang terkoneksi dengannya agar dapat saling terkoordinasi. GPS receiver berfungsi untuk membaca data posisi koordinat kendaraan berdasarkan garis bujur dan garis lintang bumi. Rangkaian relay berfungsi untuk melakukan penekanan tombol Push to Talk (PTT) secara otomatis. Sedangkan, modem FSK berfungsi untuk mengubah data digital menjadi data sinyal FSK yang akan ditransmisikan melalui radio yang berupa HT atau sebaliknya merubah data analog dari radio (HT) menjadi data digital.

\section{Microcontroller}

Microcontroller AT89S52 memiliki 8 kilo Byte Flash PEROM yang digunakan untuk menyimpan program utama yang mengatur proses transmisi data dan pembacaan data GPS. Rangkaian microcontroller AT89S52 (Mazidi, 2000) dapat dilihat pada Gambar 4.

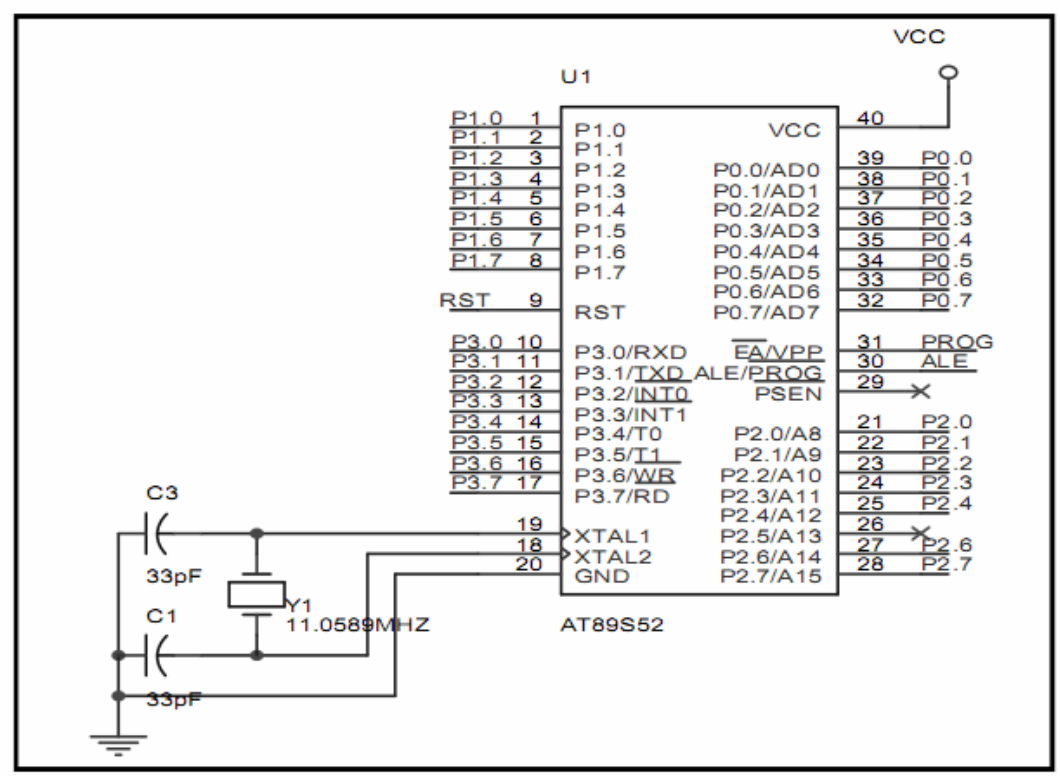

Gambar 4 Microcontroller AT89S52 


\section{Rangkaian Relay}

Dalam perangkat HT jika pengguna akan berbicara dengan pengguna lainnya, maka dia harus menekan tombol PTT terlebih dahulu. Sedangkan, dalam sistem monitoring ini tidak dimungkinkan untuk melakukan penekanan tombol PTT secara manual. Oleh karena itu, agar sistem ini dapat berjalan, maka dibuat suatu rangkaian PTT yang dapat dikendalikan oleh microcontroller dengan memanfaatkan relay. Rangkaian relay ini dapat dilihat pada Gambar 5.

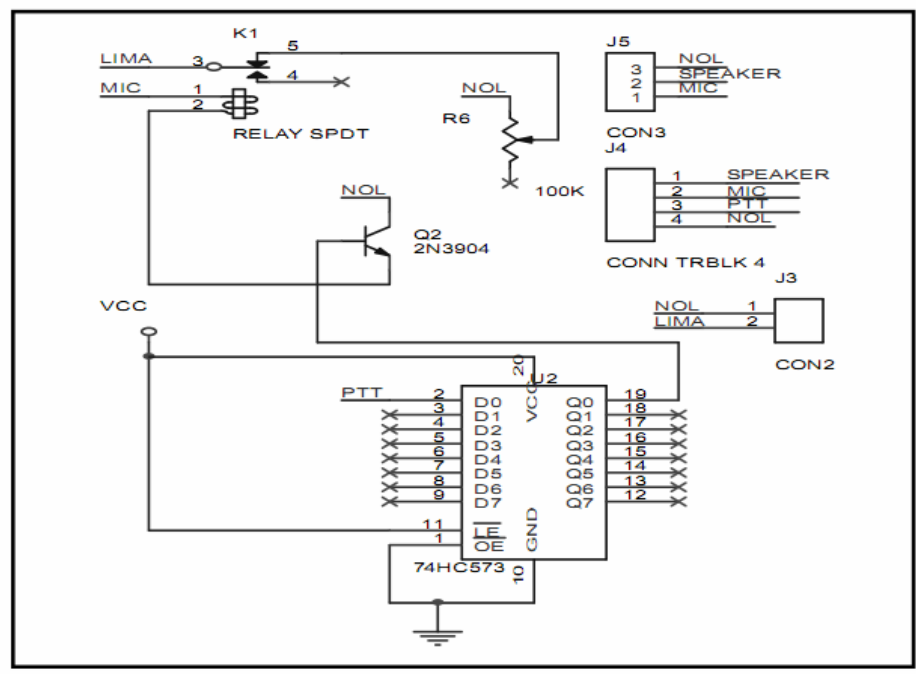

Gambar 5 Rangkaian Relay

Modem FSK Modem ini digunakan untuk mengubah data digital menjadi data analog yang dimodulasi secara FSK sehingga data digital dari microcontroller dapat dikirimkan melalui radio. Selain itu, modem ini juga berfungsi untuk mengubah data analog dari radio menjadi data digital, sehingga dapat dibaca oleh microcontroller. Rangkaian modem FSK ini dapat dilihat pada Gambar 6.

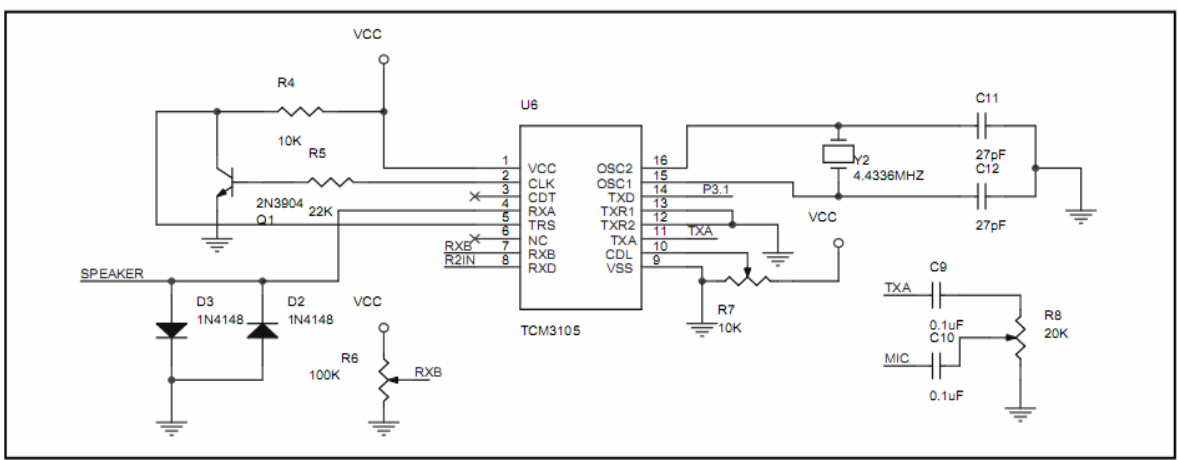

Gambar 6 Rangkaian Modem FSK 


\section{Perancangan Perangkat Lunak}

Pada sistem ini, perangkat lunak yang digunakan dibagi menjadi dua, yaitu perangkat lunak yang digunakan untuk mengendalikan perangkat keras dan perangkat lunak yang digunakan sebagai interface antara perangkat keras dengan pengguna. Perangkat lunak yang digunakan untuk mengendalikan perangkat keras disusun dengan menggunakan software Franklin Proview 32 yang ditulis dalam bahasa assembly. Sedangkan, untuk pogram yang berbasis Graphical User Interface (GUI) pada Personal Computer (PC), digunakan Software Visual Basic 6.0. Diagram alir dalam pemrograman microcontroller pada modul master ditunjukkan pada Gambar 7 .

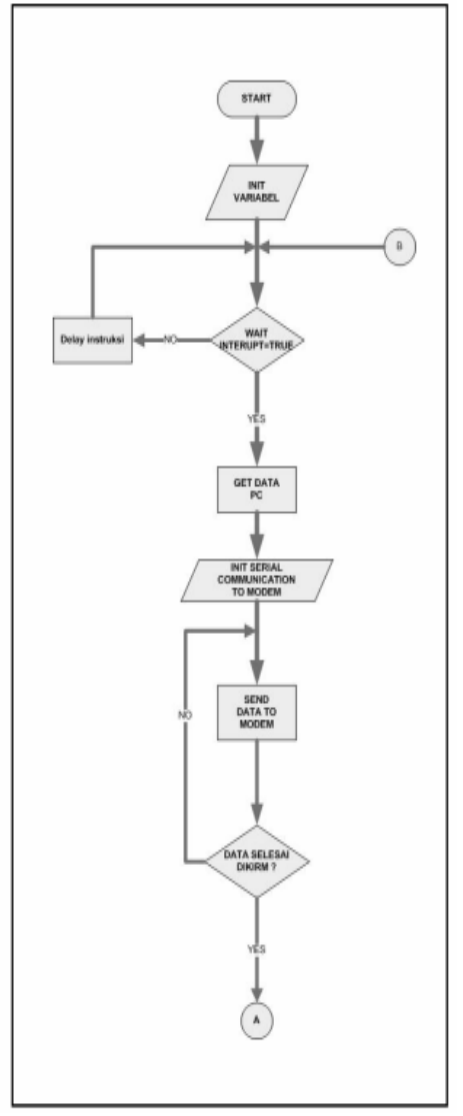

Master Bagian I

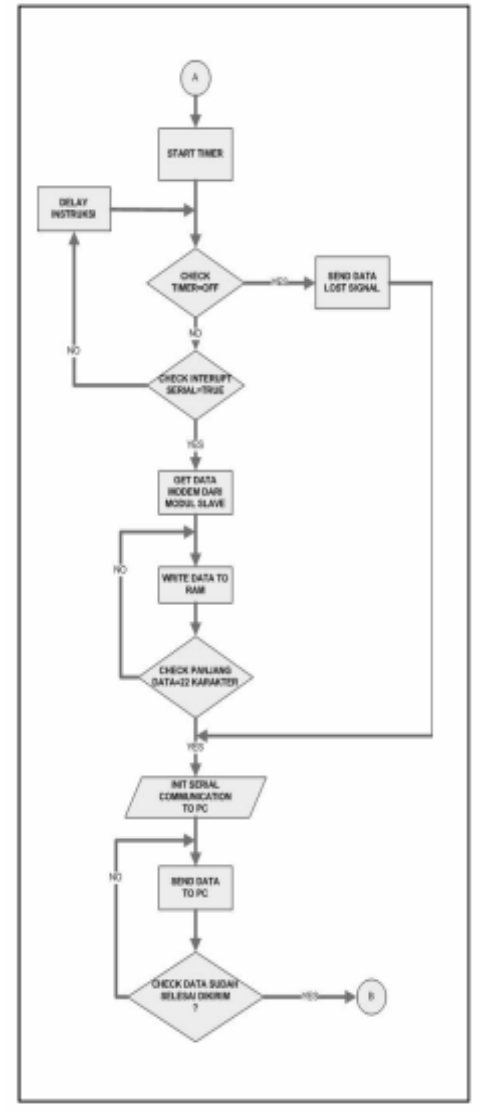

Master Bagian II

Gambar 7 Flowchart Modul Master Bagian I dan II 
Sedangkan, diagram alir pada modul slave ditunjukkan pada Gambar 8.

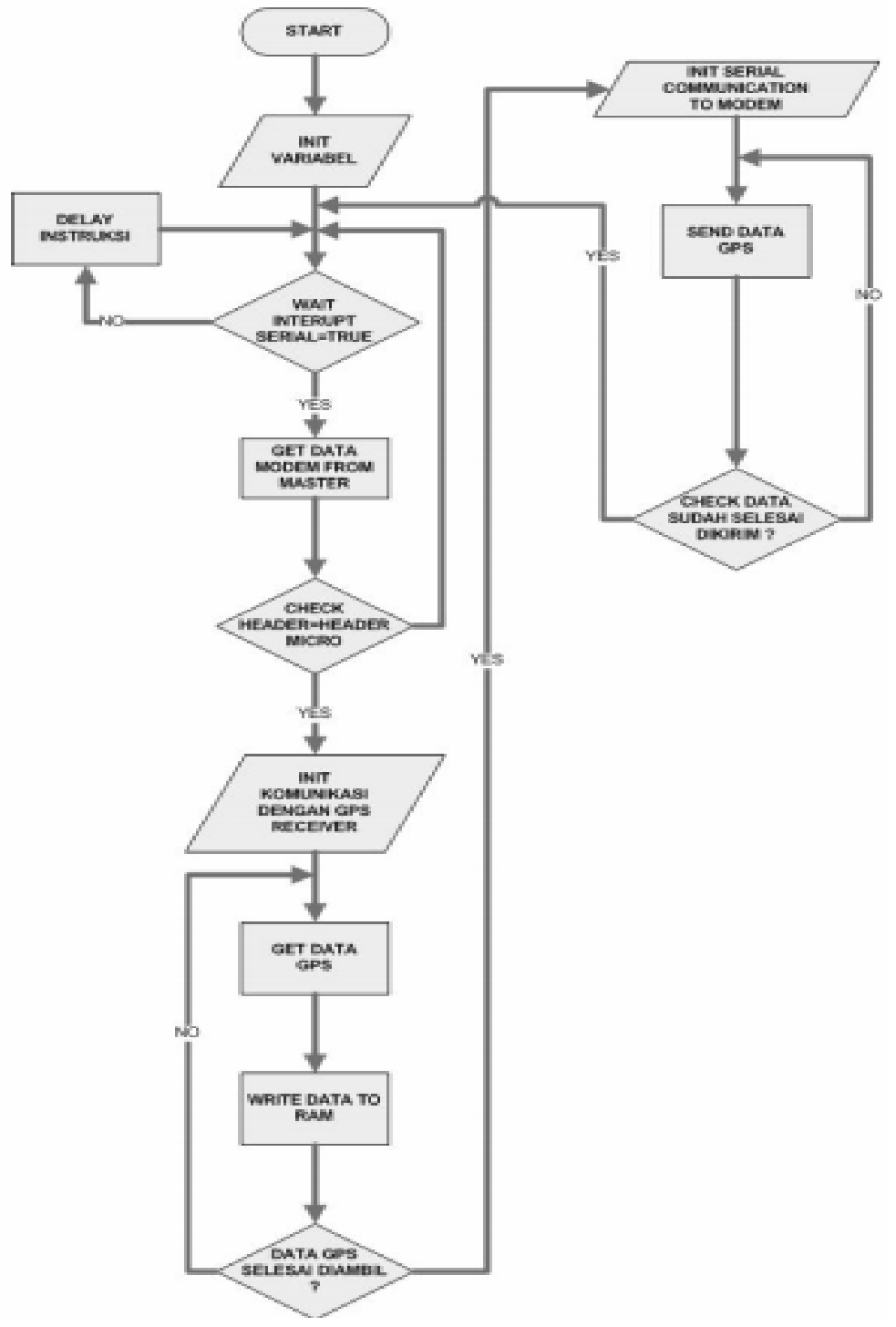

Gambar 8 Diagram Alir Pemrograman Modul Slave

\section{Program Pembaca GPS}

Program ini bertujuan untuk membaca sinyal dari GPS yang dikirimkan oleh GPS receiver. Data dari GPS receiver (Dana, 2007) dibaca melalui port serial pada microcontroller yang digunakan juga oleh modem FSK. 


\section{Program Delay}

Program delay digunakan untuk memberikan jeda waktu pada suatu proses yang akan dikerjakan oleh program pada sistem. Untuk diagram alir program GUI yang ada pada PC dapat dilihat pada Gambar 9.

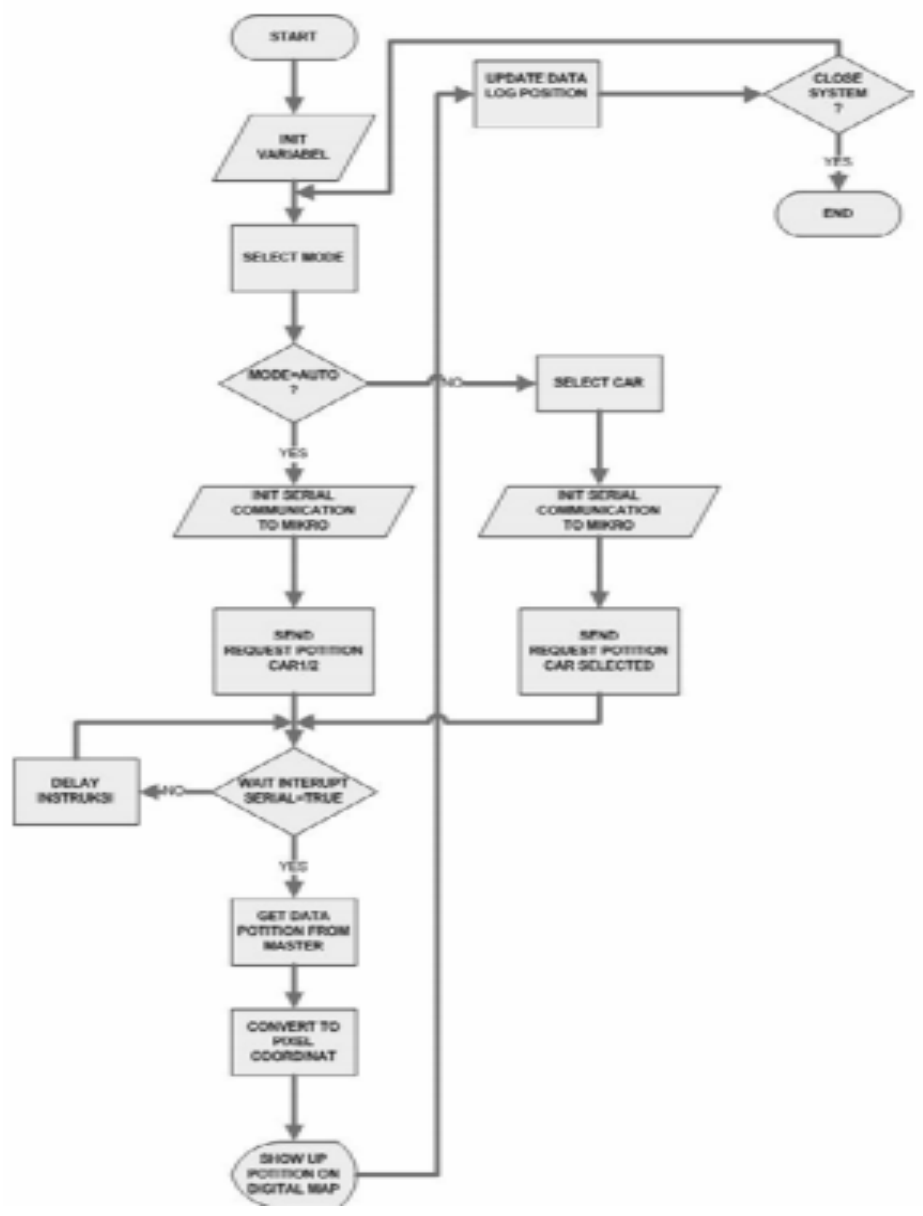

Gambar 9 Diagram Alir Program PC

\section{Program Pemilihan Jalur Serial}

Program ini digunakan untuk memilih jalur komunikasi serial antara GPS receiver dengan microcontroller, modem FSK dengan microcontroller dan PC dengan microcontroller. Program Komunikasi dengan Modem Program komunikasi dengan modem ini berfungsi untuk mengirimkan data digital dari microcontroller ke modem sehingga dapat diubah menjadi data analog yang dapat dilewatkan melalui HT. Pada program ini juga dilakukan proses setting baudrate. 


\section{Program Konversi Koordinat}

Data yang diterima oleh GPS receiver masih berupa data koordinat posisi yang berdasarkan garis lintang dan garis bujur bumi. Sedangkan peta yang digunakan untuk menampilkan posisi kendaraan pada PC menggunakan peta digital berupa koordinat picture of element (pixel). Agar posisi koordinat bumi tersebut dapat ditampilkan pada peta digital, maka diperlukan suatu program yang digunakan untuk melakukan konversi koordinat bumi menjadi koordinat pixel berdasarkan nilai skala tertentu.

\section{HASIL DAN PEMBAHASAN}

\section{Pengujian Sistem}

\section{Sistem Komunikasi}

Pengujian pengiriman data dengan komunikasi radio dilakukan dengan mengirim data serial 1 dari microcontroller yang selanjutnya dimodulasi secara FSK dan dikirimkan ke modul yang dituju. Hasil dari pengiriman data serial 1 tersebut dapat dilihat pada osiloskop yang akan menampilkan keluaran seperti pada Gambar 10 .

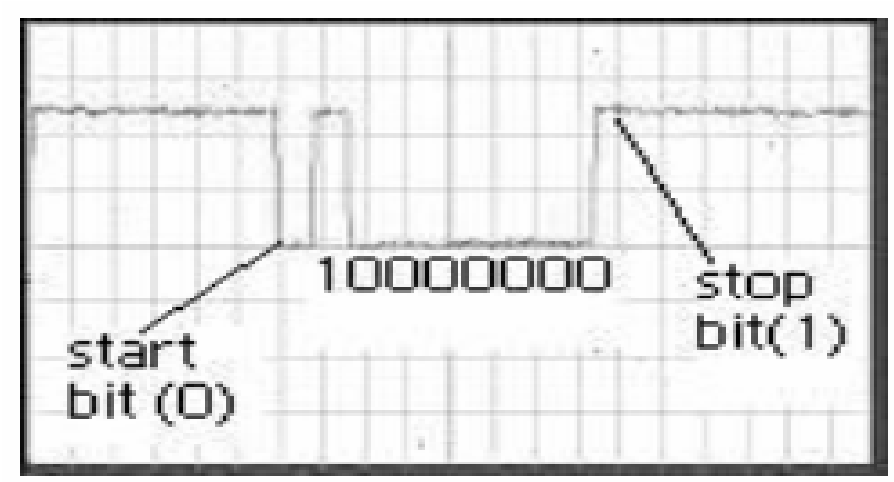

Gambar 10 Output Digital pada Osiloskop]

Data pada komunikasi serial akan dikirimkan dengan didahului oleh start bit yang berupa nilai tegangan low diikuti dengan Low Significant Bit (LSB) hingga Most Significant Bit(MSB) dari karakter kemudian akan diakhiri dengan stop bit yang berupa nilai tegangan high. Seperti pada Gambar 11 yang menunjukkan gambar pengiriman data serial 1. Sedangkan, untuk data sinyal FSK yang diterima pada modem FSK ditunjukkan pada Gambar 11. 


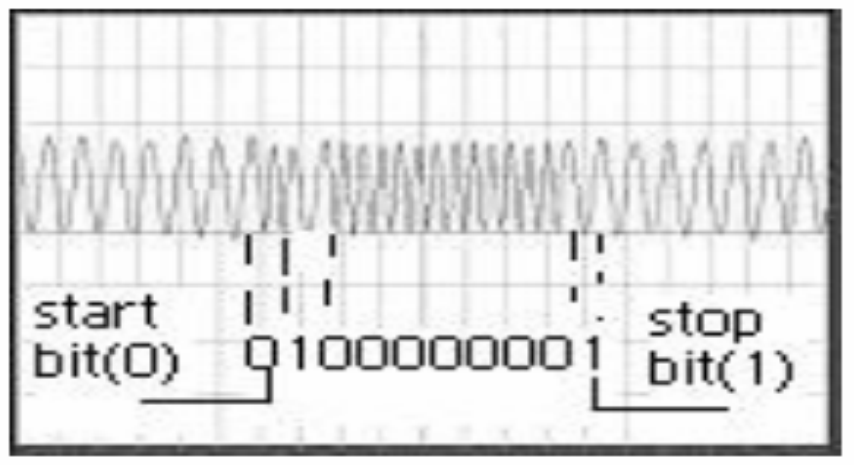

Gambar 11 Output FSK pada Osiloskop

\section{Perangkat Lunak}

Pada pengujian perangkat lunak sistem diberi request data posisi dari PC dan hasilnya dapat dilihat pada Tabel 2 dan Tabel 3.

Tabel 2 Pengujian pengiriman Request data GPS ke modul Slave 1

\begin{tabular}{cccccc}
\hline NO & $\begin{array}{c}\text { WAKTU } \\
\text { KIRIM }\end{array}$ & $\begin{array}{c}\text { WAKTU } \\
\text { TERIMA }\end{array}$ & $\begin{array}{c}\text { DELAY } \\
\text { (detik) }\end{array}$ & $\begin{array}{c}\text { LINTANG } \\
\text { SELATAN }\end{array}$ & $\begin{array}{c}\text { BUJUR } \\
\text { TIMUR }\end{array}$ \\
\hline 1 & $1: 46: 59$ & $1: 47: 04$ & 5 & S0718676 & E11246925 \\
2 & $1: 47: 43$ & $1: 47: 48$ & 5 & S0718678 & E11246925 \\
3 & $1: 53: 46$ & $1: 53: 51$ & 5 & S0718683 & E11246924 \\
4 & $23: 18: 56$ & $23: 19: 01$ & 5 & S0718681 & E11246925 \\
5 & $23: 21: 31$ & $23: 21: 36$ & 5 & S0718683 & E11246924 \\
6 & $23: 23: 31$ & $23: 23: 36$ & 5 & S0718683 & E11246920 \\
7 & $23: 32: 01$ & $23: 32: 07$ & 6 & S0718680 & E11246919 \\
8 & $2: 45: 52$ & $2: 45: 58$ & 6 & S0718717 & E11246840 \\
9 & $2: 45: 59$ & $2: 46: 04$ & 5 & S0718737 & E11246840 \\
10 & $2: 46: 06$ & $2: 46: 11$ & 5 & S0718737 & E11246839 \\
11 & $2: 46: 12$ & $2: 46: 17$ & 5 & S0718721 & E11246839 \\
12 & $2: 46: 18$ & $2: 46: 23$ & 5 & S0718702 & E11246837 \\
13 & $2: 46: 26$ & $2: 46: 31$ & 5 & S0718682 & E11246832 \\
14 & $2: 46: 54$ & $2: 46: 59$ & 5 & S0718604 & E11246826 \\
15 & $2: 47: 34$ & $2: 47: 39$ & 5 & S0718621 & E11246760 \\
16 & $2: 48: 03$ & $2: 48: 08$ & 5 & S0718565 & E11246707 \\
17 & $2: 48: 20$ & $2: 48: 25$ & 5 & S0718555 & E11246738 \\
18 & $2: 48: 26$ & $2: 48: 32$ & 6 & S0718554 & E11246747 \\
19 & $2: 48: 56$ & $2: 49: 01$ & 5 & S0718558 & E11246775 \\
20 & $6: 14: 16$ & $6: 14: 21$ & 5 & S0718712 & E11246855 \\
21 & $6: 14: 23$ & $6: 14: 28$ & 5 & S0718744 & E11246782 \\
22 & $6: 14: 43$ & $6: 14: 48$ & 5 & S0718752 & E11246784 \\
23 & $6: 14: 50$ & $6: 14: 55$ & 5 & S0718755 & E11246785 \\
24 & $6: 15: 10$ & $6: 15: 15$ & 5 & S0718763 & E11246787 \\
25 & $6: 15: 31$ & $6: 15: 36$ & 5 & S0718686 & E11246929 \\
26 & $6: 16: 27$ & $6: 16: 32$ & 5 & S0718680 & E11246918 \\
27 & $6: 16: 34$ & $6: 16: 40$ & 6 & S0718680 & E11246918 \\
28 & $6: 54: 20$ & $6: 54: 25$ & 5 & S0718685 & E11246928 \\
29 & $6: 56: 01$ & $6: 56: 06$ & 5 & S0718684 & E11246927 \\
30 & $6: 59: 34$ & $6: 59: 39$ & 5 & S0718686 & E11246927 \\
\hline & & & & &
\end{tabular}


ISSN: 1978 - 8282

Tabel 3 Pengujian pengiriman Request data GPS ke modul Slave 2

\begin{tabular}{|c|c|c|c|c|c|}
\hline $\mathrm{NO}$ & $\begin{array}{l}\text { WAKTU } \\
\text { KIRIM }\end{array}$ & $\begin{array}{l}\text { WAKTU } \\
\text { TERIMA }\end{array}$ & $\begin{array}{l}\text { DELAY } \\
\text { (detik) }\end{array}$ & $\begin{array}{l}\text { LINTANG } \\
\text { SELATAN }\end{array}$ & $\begin{array}{l}\text { BUJUR } \\
\text { TIMUR }\end{array}$ \\
\hline 1 & $1: 46: 52$ & $1: 46: 58$ & 6 & S0718690 & E11246929 \\
\hline 2 & $1: 47: 49$ & $1: 47: 54$ & 5 & $S 0718687$ & E11246928 \\
\hline 3 & $1: 52: 05$ & $1: 52: 11$ & 6 & S0718691 & $E 11246930$ \\
\hline 4 & $1: 55: 20$ & $1: 55: 25$ & 5 & S0718687 & $E 11246928$ \\
\hline 5 & $1: 55: 34$ & $1: 55: 39$ & 5 & SO 0718684 & E11 1246923 \\
\hline 6 & $1: 55: 44$ & $1: 55: 49$ & 5 & S0718686 & E11246924 \\
\hline 7 & $1: 55: 55$ & $1: 56: 01$ & 6 & $S 0718685$ & E11246923 \\
\hline 8 & $1: 56: 05$ & $1: 56: 11$ & 6 & $S 0718685$ & E11246922 \\
\hline 9 & $1: 56: 36$ & $1: 56: 42$ & 6 & S0718684 & E1 1246922 \\
\hline 10 & $1: 56: 46$ & $1: 56: 52$ & 6 & SO 0718684 & E1 1246922 \\
\hline 11 & $1: 56: 57$ & $1: 57: 02$ & 5 & SO 0718683 & E11246921 \\
\hline 12 & $23: 44: 32$ & $23: 44: 38$ & 6 & S0718683 & E11246926 \\
\hline 13 & $23: 45: 54$ & $23: 45: 59$ & 5 & S0718689 & $E 11246915$ \\
\hline 14 & $23: 46: 00$ & $23: 46: 06$ & 6 & $S 0718689$ & E11246915 \\
\hline 15 & $0: 11: 20$ & $0: 11: 26$ & 6 & S0718691 & E11246931 \\
\hline 16 & $2: 37: 17$ & $2: 37: 22$ & 5 & $S 0718689$ & E11246922 \\
\hline 17 & $2: 37: 49$ & $2: 37: 54$ & 5 & $S 0718687$ & E11246920 \\
\hline 18 & $2: 38: 39$ & $2: 38: 45$ & 6 & $S 0718682$ & E11246919 \\
\hline 19 & $2: 39: 09$ & $2: 39: 14$ & 5 & S0718687 & E1 1246921 \\
\hline 20 & $2: 39: 44$ & $2: 39: 49$ & 5 & $S 0718687$ & E11246921 \\
\hline 21 & $2: 39: 59$ & $2: 40: 04$ & 5 & $S 0718688$ & E11246921 \\
\hline 22 & $2: 40: 14$ & $2: 40: 19$ & 5 & S0718689 & E11246922 \\
\hline 23 & $2: 40: 50$ & $2: 40: 55$ & 5 & S0718689 & E11246922 \\
\hline 24 & $2: 41: 05$ & $2: 41: 10$ & 5 & SO718689 & E 11246923 \\
\hline 25 & $2: 42: 10$ & $2: 42: 15$ & 5 & $S 0718676$ & E11246920 \\
\hline 26 & $2: 42: 20$ & $2: 42: 25$ & 5 & $S 0718678$ & E11246922 \\
\hline 27 & $2: 42: 46$ & $2: 42: 52$ & 6 & SO 0718682 & E1 1246922 \\
\hline 28 & $2: 43: 17$ & $2: 43: 23$ & 5 & S0718657 & E11246916 \\
\hline 29 & $2: 43: 32$ & $2: 43: 37$ & 5 & S0718639 & E11246910 \\
\hline 30 & $2: 43: 43$ & $2: 43: 48$ & 5 & $S 0718644$ & E11246911 \\
\hline
\end{tabular}

Selanjutnya, penulis melakukan pengujian terhadap kebenaran dari data posisi yang ditampilkan pada peta digital dengan posisi real di mana user yang memegang GPS berada. Data pengujian dapat dilihat pada Tabel 4.

Tabel 4 Hasil Pengujian Posisi pada Peta dengan Keadaan Sebenarnya.

\begin{tabular}{|c|c|c|c|}
\hline $\mathrm{NO}$ & LS & B $T$ & $\begin{array}{l}\mathrm{HASIL} P \mathrm{P} d \mathrm{a} \\
P E T_{A}\end{array}$ \\
\hline 1 & $S 07331215$ & E 111278065 & $S E S \cup A I$ \\
\hline 2 & S 0731450 & E 111278075 & $S E S \cup A I$ \\
\hline 3 & $S 0731602$ & E 11278081 & $S E S \cup A$ \\
\hline 4 & S 0731448 & E 111278320 & $S E S \cup A I$ \\
\hline 5 & S 07731397 & E 1112278317 & $S E S \cup A I$ \\
\hline 6 & S 0731358 & E 11278316 & $S E S \cup A$ I \\
\hline 7 & S 0731290 & E 111278350 & $E R R \bigcirc R$ \\
\hline 8 & S 077331291 & E 11278145 & $S E S \cup A I$ \\
\hline 9 & S 0731239 & E 112788141 & $S E S \cup A I$ \\
\hline 10 & S 07331233 & E 1112779991 & $S E S \cup A I$ \\
\hline 11 & S 0731277 & E 11277990 & $S E S \cup A I$ \\
\hline 12 & S $073 \quad 1311$ & E 11277991 & $S E S U A I$ \\
\hline 13 & S 0731223 & E 11277720 & $S E S \cup A$ \\
\hline 14 & S 0731473 & E 111277708 & $S E S \cup A I$ \\
\hline 15 & S 0731472 & E 111277596 & $S E S \cup A I$ \\
\hline 16 & $S 07331029$ & E 11277596 & $S E S \cup A$ I \\
\hline 17 & S 07331029 & E 111277591 & $S E S \cup A I$ \\
\hline 18 & S $\begin{array}{lllllll}0 & 7 & 3 & 1 & 0 & 8 & 1\end{array}$ & E 111277803 & $S E S \cup A I$ \\
\hline 19 & S 077331007 & E 11277839 & $S E S \cup A$ I \\
\hline 20 & S 0730889 & E 11277842 & $S E S \cup A I$ \\
\hline
\end{tabular}




\section{Pembahasan}

Pada proses pengujian sistem komunikasi antara microcontroller dengan modem, dilakukan dengan cara mengirimkan data serial dari microcontroller melewati modem. Data tersebut kemudian dibandingkan bentuk sinyalnya dengan menggunakan osiloskop dan didapatkan bahwa data yang dikirimkan dari microcontroller dapat diubah menjadi sinyal FSK dengan benar sesuai dengan nilai bit dari data tersebut. Setelah proses komunikasi data dengan menggunakan radio berhasil, maka dilakukan pengujian waktu request data posisi sehingga didapatkan data pada Tabel 2 dan Tabel 3. Dari data tersebut dapat dihitung berapa waktu yang dibutuhkan untuk mengetahui posisi mobil pada peta digital dengan cara menghitung berapa rata-rata waku delay yang terjadi. sehingga Trata-rata untuk slave $1=154 / 30=5.133333$ dan Trata-rata untuk slave $2=156 / 30=5.2$. Dari nilai rata-rata delay tiap mobil maka dapat dihitung nilai delay sistem secara keseluruhan dengan cara meghitung nilai delay rata-rata mobil pertama dan mobil yang kedua, sehingga besarnya waktu delay $=(5.2+5.133333) / 2=5,16 \mathrm{~s}$. Sedangkan, untuk membandingkan data posisi pada peta dengan keadaan sebenarnya dilakukan dengan cara pembacaan data GPS pada posisi yang sudah ditentukan kemudian dilakukan proses pembacaan data dari pusat. Percobaan ini dilakukan sebanyak 30 kali dan didapatkan bahwa dari 30 kali. percobaan sistem ini mengalami kesalahan data posisi yang melebihi akurasi dari GPS sebanyak 1 kali. Dengan data tersebut, maka tingkat keakuratan dapat dihitung dengan cara :

\section{Akurasi $=29 / 30 \times 100 \%$ \\ Sehingga didapatkan akurasi sebesar $95 \%$}

\section{KESIMPULAN}

Setelah melakukan penelitian ini, penulis mengambil kesimpulan sebagai berikut: (1) sistem ini memiliki tingkat keakuratan sebesar 95 persen dengan tingkat error sebesar 5 persen, (2) sistem yang dibuat telah dapat mengolah data serta memetakannya ke dalam PC Mapping Software dengan akurat, (3) waktu yang dibutuhkan dari proses request hingga mendapatkan data lokasi dan menampilkannya ke dalam map kurang lebih sekitar 5.16 detik, tergantung pada respon HT, (4) perhitungan pada proses pemetaan didasarkan pada peta yang didapat, untuk peta lain dapat dilakukan dengan sampling dan pengukuran ulang. 


\section{DAFTAR RUJUKAN}

1). Brey, B. B. 2002. Mikroprosesor Intel : 8086/8088, 80186/80188, 80286, 80386, 80486, Pentium, dan Pentium pro : Arsitektur, Pemrograman Antarmuka Edisi kelima Jilid I. Jakarta: Erlangga.

2). Dana, P.H. 2007. How GPS Work, (online), (http:/www.colorado.edu/ geography/gcraft/notes/gps/gps_f.html, diakses pada $19 \mathrm{Mei}$ 2007).Mazidi, M.A. 2000. The 8051 MICROCONTROLLER \& Embedded System. New Jersey: Printice Hall.

3). Noname, 2007. what is GPS, (online), (http:// en.wikipedia.org/wiki/ Gps, diakses pada 13 Mei 2007). 